\title{
THE ROLE OF DEMAND RESPONSE IN DEFAULT SERVICE PRICING
}

\author{
Galen Barbose and Chuck Goldman, LBNL \\ Bernie Neenan, Neenan Associates
}

Dynamic retail electricity pricing, especially real-time pricing (RTP), has been widely heralded as a panacea for providing much-needed demand response in electricity markets. However, in designing default service for competitive retail markets, demand response often appears to be an afterthought. But that may be changing as states that initiated customer choice in the past 5-7 years reach an important juncture in retail market design.

Most states with retail choice established an initial transitional period, during which utilities were required to offer a default or "standard offer" generation service, often at a capped or otherwise administratively-determined rate. Many retail choice states have reached, or are nearing, the end of their transitional period and several states have adopted an RTP-type default service for large commercial and industrial (C\&I) customers. Are these initiatives motivated by the desire to induce greater demand response, or is RTP being called upon to serve a different role in competitive markets? Surprisingly, we found that in most cases, the primary reason for adopting RTP as the default service was not to encourage demand response, but rather to advance policy objectives related to the development of competitive retail markets. However, we also find that, if efforts are made in its design and implementation, default RTP service can also provide a solid foundation for developing price responsive demand, creating an important link between wholesale and retail market transactions.

This paper, which draws from a lengthier report, describes the experience to date with default RTP in the U.S., identifying findings related to its actual and potential role as an instrument for cultivating price responsive demand [1]. For each of the five states currently with default RTP, we conducted a detailed review of the regulatory proceedings leading to its adoption. To further understand the intentions and expectations of those involved in its design and implementation, we also interviewed regulatory staff and utilities in each state, as well as eight of the most prominent competitive retail suppliers operating in these markets which, together, comprised about $60-65 \%$ of competitive C\&I sales in the U.S. in 2004 [2].

\section{Overview of default RTP service in the U.S.}

RTP is currently the default service for the largest C\&I customers of eleven investor-owned utilities (IOU) in the U.S. and is planned or proposed for fifteen others (see Table 1). In most cases, it has been implemented through a regulatory process whose central purpose was to establish the "post-transition" supply service for individual utilities or all utilities in a state, following the expiration of standard offer rate caps and/or utility contracts with generators to supply customers that have not switched. These regulatory processes have typically been guided by a set of broad statutory mandates (e.g., that default service be "market-based") and involved a large number of stakeholders attempting to address and resolve a wide range of issues.

Based on our interviews with stakeholders involved in these proceedings and from our review of the regulatory record, itself, it is evident that adoption of RTP as the default service has been motivated largely by goals related to retail market development. What makes RTP an attractive candidate in this regard? First, RTP encourages switching by motivating customers that do not want to face hourly spot market prices to seek out hedged supply contracts with competitive suppliers. Second, RTP avoids the 
use of class average load profiles for commodity pricing, and with it, intra-class cross-subsidies that distort the retail market. Third, RTP allows for placing minimal switching restrictions on customers remaining on default service. Fourth, RTP limits the ability of competitive firms to arbitrage default service by offering customers contracts for only part of the year when supply costs are below average, and then switches them back to an average priced default service to avoid the high-priced supply periods. Finally, RTP is never out of synch with current market conditions, which can be an issue with fixed price, long term contracts developed through a "market-based" auction or RFP process. Thus, when considering whether or not to enter a particular market, retail suppliers can better judge whether they will have enough headroom to beat the default rate, should wholesale prices rise.

Table 1. Default RTP service in the U.S.

\begin{tabular}{|c|c|}
\hline State & Status of Default Service RTP Implementation \\
\hline New Jersey & Implemented by all four IOUs in August 2003 \\
\hline Maryland & $\begin{array}{l}\text { Implemented by BGE from June 2002-June } 2003 \text { (superseded by statewide default service) } \\
\text { Implemented by BGE, PEPCO, and Delmarva in June } 2005 \\
\text { Implemented by Allegheny Power in January } 2006\end{array}$ \\
\hline Pennsylvania & $\begin{array}{l}\text { Implemented by Duquesne in January } 2005 \\
\text { Proposal currently under consideration for the other } 10 \text { IOUs in the state }\end{array}$ \\
\hline New York & $\begin{array}{l}\text { Implemented by NMPC in November } 1998 \\
\text { Implemented by CHG\&E in May } 2005 \\
\text { Other four NY IOUs directed to file default RTP tariffs in } 2006\end{array}$ \\
\hline Illinois & $\begin{array}{l}\text { Scheduled for implementation by ComEd in January } 2007 . \\
\text { RTP has been offered as an optional (opt-in) service by all Illinois IOUs since } 1998 .\end{array}$ \\
\hline
\end{tabular}

\section{Default RTP tariff design and implementation details}

The default RTP tariffs currently in place have several features that are important for understanding their potential role as a source of price responsive demand. First, all employ an unbundled and unhedged commodity (energy) charge. Energy costs are calculated for each customer on an hourly basis by multiplying its usage in that hour by the prevailing hourly market price. Niagara Mohawk (NMPC) and Central Hudson Gas \& Electric (CHG\&E) index the hourly prices for default RTP to the New York Independent System Operator (NYISO)'s locational, day-ahead energy market, which are published by 4:00 p.m. on the prior day. In contrast, utilities in New Jersey, Maryland, and Pennsylvania use the PJM real-time spot market price to set the default RTP hourly prices. Customers on these rates do not know the exact prices they will be charged until after-the-fact since the hourly real-time PJM prices are not known until after the applicable hour has elapsed. ${ }^{\text {a }}$

Although the first utilities to adopt default RTP did so only for the very largest customers (e.g., $>1.5$ MW billing demand), default RTP has been adopted for increasingly smaller customers (see Table 2). For example, at Niagara Mohawk, the size threshold for large C\&I customers was peak demand of 2 MW or greater. The New York PSC recently ordered Niagara Mohawk to file an RTP-type default service tariff for customers with peak demand of approximately $300 \mathrm{~kW}$ or greater. Regulatory commissions in several other states have implemented default RTP for mid-sized C\&I customers: e.g., eligibility is over $600 \mathrm{~kW}$ in Maryland and over $300 \mathrm{~kW}$ for Duquesne. Several factors have driven the choice of a particular customer size threshold. In many cases, it has reflected some consideration (usually informal) of customers’ ability to either manage the default pricing risks or find a less risky alternative. In some cases, the capabilities of the existing metering and billing infrastructure has also

\footnotetext{
${ }^{\text {a }}$ Real-time prices are set every five minutes. The hourly PJM price is a weighted average of the composite five-minute prices.
} 
been a factor, although regulators in several jurisdictions (New Jersey and Maryland) did decide to significantly expand interval metering deployment in conjunction with default RTP. ${ }^{\text {b }}$

Another important design issue is whether the utility offers another alternative supply service to customers in the default RTP class, and if so, for how long (see Table 2). Duquesne offers a temporary fixed price, full requirements service (scheduled to expire by mid-2007) that customers in the default RTP class can elect during specified enrollment windows. In Maryland, large customers were provided with a fixed price, full requirements default service for a one-year period, during which RTP was an optional alternative. After that year, RTP became the default and only service option for large customers that had not switched to a competitive supplier. NMPC took a different approach when it implemented default RTP default service in 1998. Customers subject to default RTP had a one-time opportunity, before the default RTP tariff was implemented, to contract for fixed-price peak and offpeak load blocks for up to five years. Customers that opted for this temporary hedged service with NMPC could purchase their residual load either at the default RTP rate or through a competitive retail supply contract.

Table 2. Default RTP Tariff Design and Implementation Details

\begin{tabular}{|c|c|c|c|}
\hline State or Utility & $\begin{array}{l}\text { Commodity } \\
\text { Charge }\end{array}$ & $\begin{array}{c}\text { Applicable } \\
\text { Customer Class }\end{array}$ & $\begin{array}{c}\text { Other Utility Supply Options for Customers } \\
\text { in the Default RTP Class }\end{array}$ \\
\hline New Jersey & \multirow{3}{*}{$\begin{array}{l}\text { Real-time } \\
\text { market price }\end{array}$} & $>1,250 \mathrm{~kW}$ & ( \\
\hline Maryland & & $>600 \mathrm{~kW}$ & None \\
\hline $\begin{array}{l}\text { Pennsylvania } \\
\text { (Duquesne) }\end{array}$ & & $>300 \mathrm{~kW}$ & A fixed-price service offered until mid-2007 \\
\hline NMPC & \multirow{3}{*}{$\begin{array}{l}\text { Day-ahead } \\
\text { market price }\end{array}$} & $>2,000 \mathrm{~kW}$ & $\begin{array}{l}\text { Customers offered a one-time opportunity in } 1998 \text { to contract for } \\
\text { fixed-price, TOU load blocks, for up to five years }\end{array}$ \\
\hline CHG\&E & & $>500 \mathrm{~kW}$ & None \\
\hline ComEd & & $>3,000 \mathrm{~kW}$ & None (after default RTP implementation in 2007) \\
\hline
\end{tabular}

\section{Customer Exposure to Hourly Spot Market Prices in Competitive Retail Markets}

\section{Customer enrollment in Default RTP service}

A relatively small percentage of customers have chosen to remain on RTP when it is the default service. Less than $15 \%$ of the eligible load remains on the default RTP rate for seven utilities in Maryland, New Jersey and Pennsylvania, while three utilities report that 25-35\% of the load remains on default RTP (see Figure 1). The other customers in the class have either switched to a competitive supplier or, in the case of Duquesne, opted onto the temporary fixed-price utility service. Yet, despite the small percentage of customers remaining on default RTP, the magnitude of load paying default RTP, and therefore market spot prices, is not inconsequential. Among half of the ten utilities, more than $100 \mathrm{MW}$ has remained on default RTP tariff; and the total enrollment in default RTP across all utilities is almost 1,000 MW. However, default RTP rates have been implemented only within the last several years. It remains to be seen how enrollment changes over time as wholesale market conditions evolve and as customers have more time to shop for alternative arrangements with competitive suppliers and perhaps a wider range of opportunities. ${ }^{\mathrm{c}}$

\footnotetext{
${ }^{\mathrm{b}}$ New Jersey utilities were directed to install interval meters for all customers $>750 \mathrm{~kW}$, even though the customers initially subject to default RTP were all much larger.

' As one indication of what to expect, NMPC's default RTP service, the oldest of the group, has seen a steady decline in enrollment each year, from 72\% of the class in 2000 to about one-third in 2004 .
} 
What do the participation rates in default RTP tell us about customers' willingness to face hourly pricing? Certainly, some customers have responded to the prospect of being placed on default RTP by seeking out alternative supply arrangements with competitive providers. This, of course, was the intended effect. However, switching is not necessarily indicative that the customer has rejected paying market-based prices. Many customers have opted for competitive supply contracts that incorporate hourly pricing and offer a discount off of the default rate or other, more attractive provisions. Moreover, it is important to consider that in several cases (e.g., Duquesne and the Maryland utilities), much of the switching in the default RTP class occurred prior to implementing default RTP. In fact, some state public utility commissions have apparently taken high switching rates as evidence that a robust retail market has developed, and have concluded that therefore adopting RTP as the default service would not pose an undue burden. Conversely, some customers have remained on default RTP only for want of a more attractive alternative. Thus, it would also be erroneous to assume that customers remaining on default RTP are necessarily intending to respond to those prices. ${ }^{\mathrm{d}}$

What factors explain the substantial differences in default RTP participation rates among the ten utilities, which range from $3 \%$ to $35 \%$ of the load in the applicable customer class? First, the utility service territories are at varying degrees of retail market development, and so customers across the default RTP classes may have unequal access to attractive competitive alternatives. Details of the default service implementation and tariff design are likely important as well. For example, Duquesne is the only utility that currently offers a fixed price service to customers in the default RTP class, and not unexpectedly, enrollment in its default RTP rate is the lowest among the ten utilities ( 3\%) while 25\% of the load has opted for the fixed price utility service. Another key tariff design feature is the advance notice with which customers receive hourly prices. The fact that NMPC's and CHG\&E's default RTP rates have relatively high enrollment rates can be attributed, at least in part, to the fact that their customers receive prices a day in advance of when they are effective, while their counterparts in Maryland, and Pennsylvania have no advance notice of hourly prices.

\footnotetext{
d Interviews with customers remaining on NMPC's default RTP service found that many declare that they cannot respond to prices but have remained on default RTP because they reckon that the premiums associated with hedged services are excessive given the risks.
} 


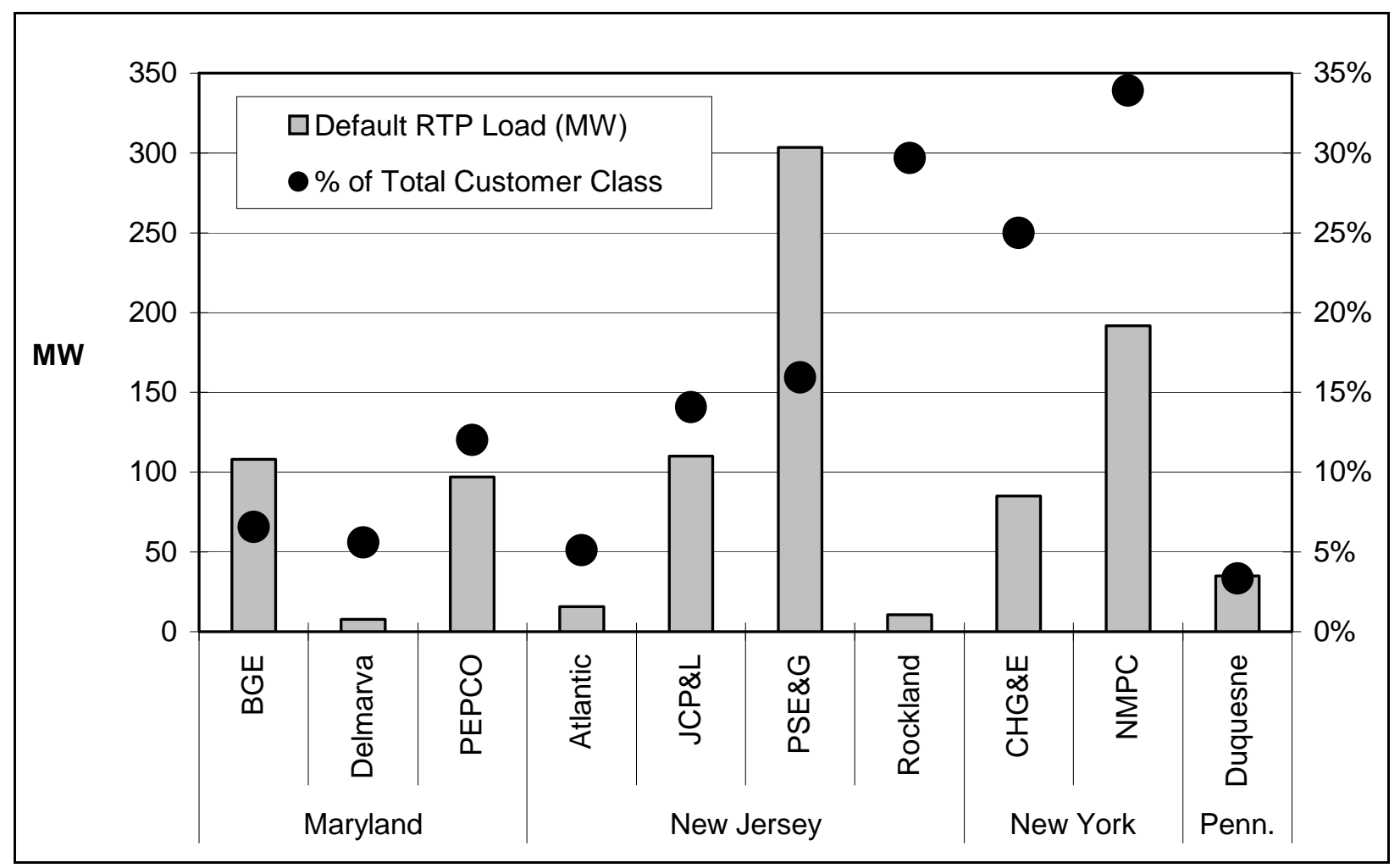

Figure 1. Enrollment in Default RTP Service $(2004 / 2005)^{\mathrm{e}}$

\section{Dynamic pricing arrangements offered by competitive retail suppliers}

We asked the eight competitive retailers that were interviewed to describe the types of pricing arrangements offered to C\&I customers. All indicated that they offer customers the option to purchase all of their commodity (energy) requirements at hourly prices indexed to the real-time or day-ahead spot market. Several retailers market these pricing arrangements as providing a "guaranteed savings" off of the default RTP service, by beating the retail adder or fixed-price components (e.g., for installed capacity) in the default RTP rate.

All suppliers reported that they offer financial hedging options in combination with their hourly pricing product, although none indicated that they offer financial hedges, such as contracts for differences or price caps or straddles, to customers remaining on default RTP. Suppliers reported that a "block-andindex" product is becoming increasingly popular for customers willing to expose a portion of their load to hourly market prices. In this arrangement, customers contract for blocks of load at a fixed $\$ / \mathrm{kWh}$ price and pay hourly spot market prices for all of their usage above the block level (see Figure 2). Suppliers typically offer customers some degree of flexibility in customizing the shape of the load block (i.e., the hours and days of the week covered by the block) as well as the size of the load block relative to their total load. ${ }^{g}$ Some suppliers treat the load block as a take-or-pay obligation. Others credit

\footnotetext{
${ }^{\mathrm{e}}$ Data shown in the figure represent enrollment at the time that we conducted our research, between late 2004 and early 2005.

${ }^{\mathrm{f}}$ Many default RTP rates include a retail adder, which is a mark-up above wholesale spot market prices intended to provide headroom for competitive suppliers. Alternatively, some states have opted to provide an explicit "shopping credit" for customers that switch to a competitive supplier, which fulfills the same function as a retail adder.

${ }^{\mathrm{g}}$ A typical configuration, according to one supplier, is for customers to purchase fixed price blocks for peak and off-peak periods, with the peak period block covering at least $75 \%$ of their peak usage. This is consistent with the observed hedging decisions by Niagara Mohawk’s large C\&I customers, who, when offered a one-time choice to purchase fixed-price peak and off-peak load blocks, typically chose to hedge $60-80 \%$ of their peak period load [3].
} 
customers for deviations in usage below the block level hour-by-hour at the prevailing spot market price, the same way they settle load above that level. From the perspective of facilitating price responsive demand, this pricing structure is advantageous, because the customer faces an efficient marginal price for incremental changes in usage, no matter what their overall usage level.

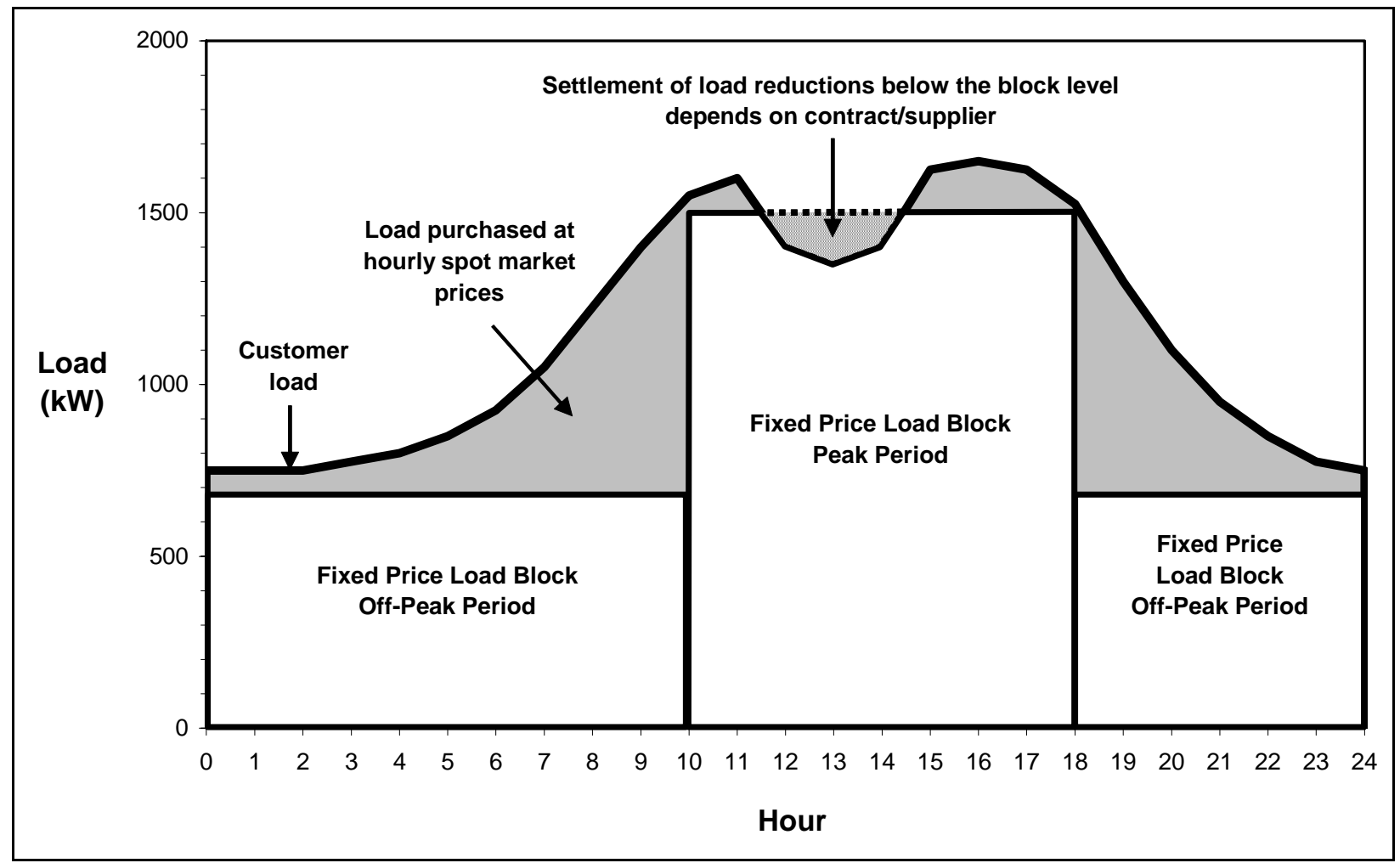

Figure 2. A Block-and-Index Pricing Arrangement

\section{Market penetration of hourly, spot market-indexed pricing arrangements}

We asked retail suppliers to estimate the percentage of their large C\&I load in various regions either on a block-and-index arrangement or fully exposed to hourly spot market prices (see

Table 3). Reported market penetration rates ranged from 50-75\% in New Jersey, while values reported for most other regions were lower, typically in the range of $5-25 \%$. ${ }^{\text {h }}$

Differences among regions in the penetration of hourly spot market indexed pricing arrangements can be attributed to several factors. First, when the interviews were conducted in the fall of 2004, default RTP service was in place in New Jersey and in NMPC's service territory, but not yet in any other regions. To the extent that customers seek out competitive supply arrangements with a similar pricing structure to the default rate, the market penetration rate of spot market products would therefore be higher for New Jersey and NMPC. Second, the customer size threshold for default RTP, which we used to define the “large” C\&I class, differs significantly among the states. In New Jersey and NMPC's service territory, the customer size thresholds are relatively high compared to Maryland. If, as many suppose, larger customers are more predisposed to hourly pricing, then we would expect higher market penetration rates among these customer populations. Finally, the composition and mix of business types may vary across utilities.

\footnotetext{
${ }^{\mathrm{h}}$ In comparison, recent market research by Suez Energy Resources found that roughly 20\% of C\&I customers interviewed in Texas and in New England indicated a preference for spot market indexed contracts over fixed price contracts [4, 5].
} 
When asked about factors driving customer demand for hourly-priced supply contracts, all of the suppliers asserted that, in general, customers' ability and willingness to respond to hourly prices was not a significant driver. Instead, some customers are looking for a guaranteed savings off of the default service rate, which competitive suppliers can potentially offer by beating the retail adder or fixed price components in the default RTP rate. Other customers are simply "riding the market," waiting until the time is right to lock in a fixed price contract. And last, some customers have decided that the premium for a fixed price, full-requirements service is greater than the value they place on the price certainty such contracts provide. Regardless of what factor each thought was most dominant, almost all suppliers suggested that much of the current demand for spot market indexed arrangements was temporary, due to low spot market volatility and relatively mild weather, and would wane over the long run. ${ }^{\mathrm{i}}$

Table 3. Market penetration of hourly spot market indexed pricing arrangements ${ }^{\mathrm{j}}$

\begin{tabular}{|lcc|}
\hline \multicolumn{1}{|c|}{ Large C\&I Market } & Supplier & $\begin{array}{c}\text { Percent of Large C\&I Load Facing Hourly Spot } \\
\text { Market Prices on the Margin }\end{array}$ \\
\hline NMPC SC-3A class & 2 & $>90 \%$ \\
\hline \multirow{2}{*}{ New Jersey CIEP class } & 2 & $75 \%$ \\
& 5 & $50-60 \%$ \\
\multirow{2}{*}{ Maryland Type III class } & 6 & $50 \%$ \\
\hline \multirow{2}{*}{ PJM region } & 5 & $5 \%$ \\
& 6 & $20 \%$ \\
\hline NYISO region & 3 & $10 \%$ \\
\hline ISO-NE region & 4 & $<25 \%$ \\
\hline
\end{tabular}

\section{Estimated total load exposed to hourly spot market indexed prices}

In states with default RTP and retail choice, two groups of customers face hourly prices: those that have remained on default RTP and those that are purchasing their supply from a competitive provider through some type of hourly pricing arrangement. State PUCs typically provide information on customers and load remaining on default RTP, as part of efforts to track switching rates by customer class. However, very little information is currently available in the public domain regarding retail suppliers' mix and type of contracts.

To fill this void, we developed lower and upper bound estimates of the amount of load facing hourly spot market prices through competitive retail supply contracts among three C\&I customer populations: the New Jersey CIEP class, the Maryland Type III class, and the NMPC SC-3A class. We derived these estimates from individual suppliers' statements about the portion of their large C\&I load exposed to hourly pricing, from surveys with customers in NMPC's service territory, and from public data on supplier market share.

These three large C\&I customer classes represent approximately $10-20 \%$ of the total system peak in their respective state or service territory. Combining our estimates of the total market penetration of spot market indexed competitive supply contracts with public data on enrollment in default RTP service,

\footnotetext{
${ }^{\mathrm{i}}$ One might also draw the opposite conclusion: that demand for spot market indexed prices will increase with spot market volatility as customers find that they can hedge their exposure more cost-effectively by adjusting their load in response to hourly prices than with a financial hedge or fixed price supply contract. If movement occurs in both directions, the net impact would obviously depend on the relative magnitude of each effect.

${ }^{\mathrm{j}}$ The NMPC SC-3A class, the New Jersey CIEP class, and the Maryland Type III class refer to the default RTP service classes in each respective region.
} 
we estimate that $6-10 \%$ of the system peak load in New Jersey, 3-5\% of the system peak in Maryland, and $4-8 \%$ of the system peak in NMPC's service territory is currently facing hourly spot market prices on the margin (see Figure 3).

Given this information, the key question from the perspective of characterizing the associated price responsive demand is: How responsive are these customers to changes in hourly spot market prices?

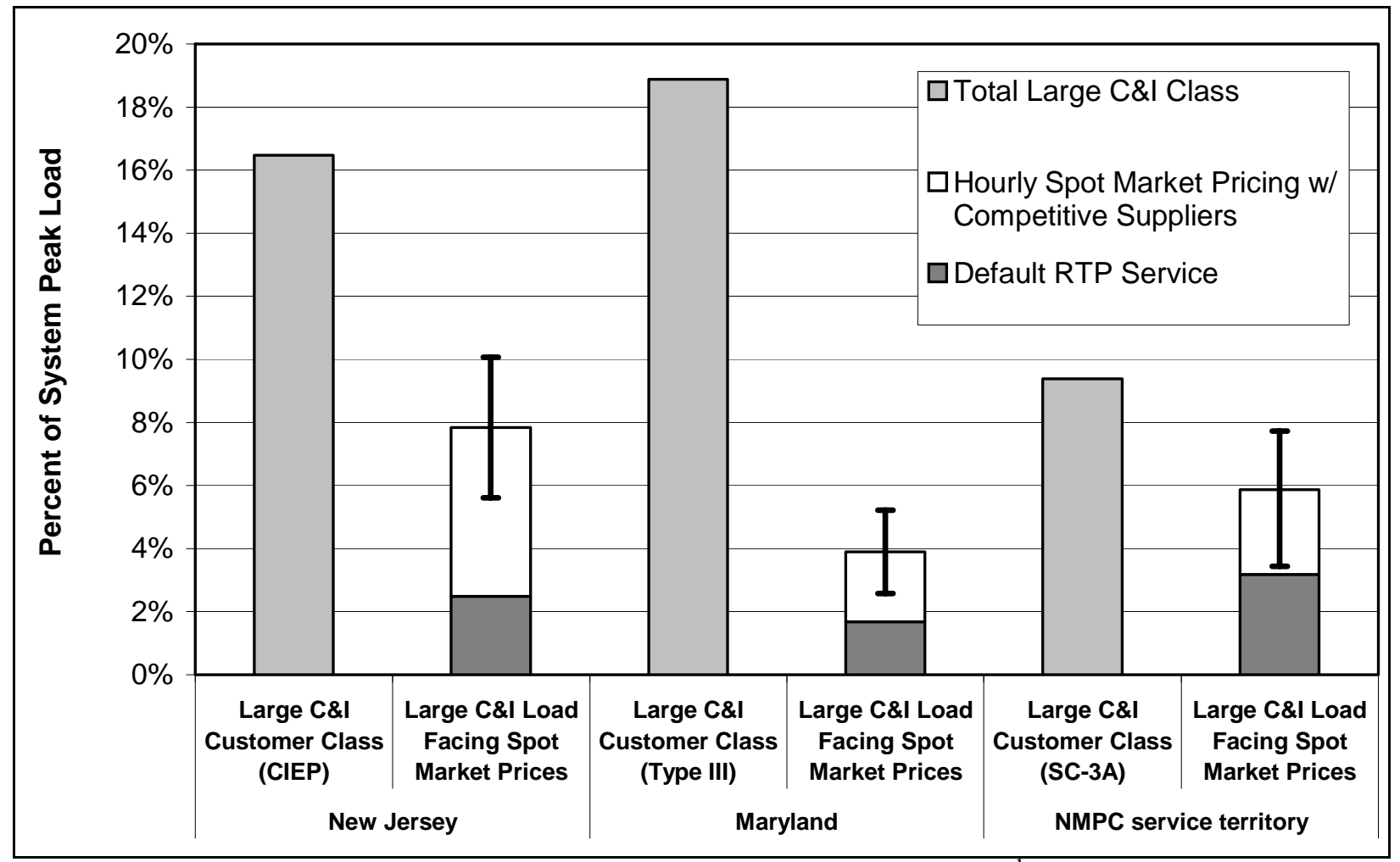

Figure 3. Total Load Facing Hourly Spot Market Prices on the Margin. ${ }^{k}$

\section{Price Response from Customers Facing Hourly Spot Market Prices}

Of the default RTP tariffs currently in place, only NMPC has been subject to formal evaluation of customers' price response. A recent analysis found that, in aggregate, Niagara Mohawk's customers that were exposed to hourly prices either through the default RTP tariff or in their contract with competitive retailers reduced their load by an amount equal to approximately $10 \%$ of their combined billing demand, when peak period prices are five times higher than off-peak prices [3]. Based on the total load currently enrolled on the NMPC RTP rate, a load reduction of this magnitude corresponds to about $0.6 \%$ of the utility's total system peak.

The default RTP tariffs currently offered in Maryland, New Jersey and Pennsylvania are indexed to the real time spot market and customers do not know for certain the hourly prices that they will be charged until after the fact. The utility and regulatory staff interviewed from these jurisdictions noted that there has been no formal study of customer's price responsiveness and offered their view that customers currently on default RTP service are probably not actively monitoring or responding to hourly prices.

\footnotetext{
${ }^{\mathrm{k}}$ The error bars reflect our high and low estimates for the amount of load facing hourly prices through competitive supply contracts.
} 
Thus, no firm conclusions can be drawn at this time about whether, or to what extent, customers remaining on the default RTP service in New Jersey, Maryland, and Duquesne's service territory respond to hourly prices.

Data on the price responsiveness of customers facing hourly prices through competitive supply contracts is similarly sparse. The suppliers we interviewed indicated that they have not formally analyzed the load response of customers on hourly pricing, and that they do not account for their price response in scheduling or procurement activities. Most shared the view that the majority of customers on hourly pricing do not modify their usage in response to hourly prices. Several suppliers indicated that a small number of customers with onsite generation or discrete production processes do respond to hourly prices.

Many suppliers suggested that customers have elected to pay hourly market-based prices for reasons unrelated to price response and are not particularly interested in or capable of managing their load in response to hourly prices. Perhaps as a consequence of such views, retail suppliers generally offer few products or services to help customers on hourly pricing cultivate their price response capabilities, nor do suppliers highlight potential cost savings from load response in their marketing activities. ${ }^{1}$

\section{A Comparison to Utility and ISO/RTO Demand Response Programs}

Having customers face hourly commodity prices is one type of mechanism for stimulating price responsive demand. Demand response (DR) programs, which offer explicit payments to customers for load reductions, represent a different, and potentially complementary, type of approach.

DR programs can be classified according to whether they are used to elicit load reductions in response to reliability conditions ("emergency programs") or to economic conditions such as high spot market prices (“economic programs”) as well as the type of commitment required of the customer and the form of payment offered.

- Call Option Load Reduction Programs provide customers with an up-front payment in exchange for making a standing commitment over a designated time frame (e.g., the summer season) to reduce their load if requested. Customers that do not curtail when requested are assessed non-compliance penalties.

- $\quad$ Scheduled Load Reduction Programs provide customers with payments based on their actual load reductions. To receive such payments, customers must commit to reducing their load by a specific amount during a designated time period (e.g., the following day from 2:00 - 6:00 PM).

- Voluntary Load Reduction Programs require no prior customer commitment and provide payments based on customers' actual load reductions.

\footnotetext{
${ }^{1}$ Several suppliers reported that they do offer internet-based access to hourly load data or "price alert” services. However, none integrate any type of technical assistance (e.g., facility audits or analyses of load response technologies/strategies) into their commodity service. Most of the suppliers in our sample do have a separate energy services group within the company or an affiliated energy services company (ESCO) that offers technical services to help customers reduce their energy costs. However, most suppliers indicated that their ESCO affiliate or group focuses primarily on energy efficiency measures. Moreover, none of the suppliers currently integrate their ESCO services with their retail supply function or have any formal or routine process for marketing ESCO services to customers on hourly pricing or vice-versa.
} 
Large C\&I customers in states with default RTP have the opportunity to participate in a DR programs offered by either their utility or the RTO/ISO. In 2004, enrollment in half of these programs was equal to at least $1-5 \%$ of the corresponding utility's or state's system peak load (see Figure 4). Note that DR program enrollment is reported in terms of the load reduction quantity that customers nominate when they enroll in the program, unlike enrollment in RTP, which is reported in terms of participants' total load.

But how have these DR programs actually performed? Emergency DR programs have demonstrated the ability to elicit load reductions in the range of $1-3 \%$ of the respective utility or state's system peak. In general, call option programs have elicited load reductions at or near participants' contracted level, because of customers' incentive to avoid non-compliance penalties. Voluntary load reduction programs have also elicited sizable reductions relative to participants' nominated amount when high incentive payments are offered (e.g., the \$500/MWh floor price in NYISO’s EDRP and PJM's emergency LRP). In comparison, scheduled load reduction programs thus far have generated quite modest load reductions relative to the amount that participants nominated upon enrolling in the program.

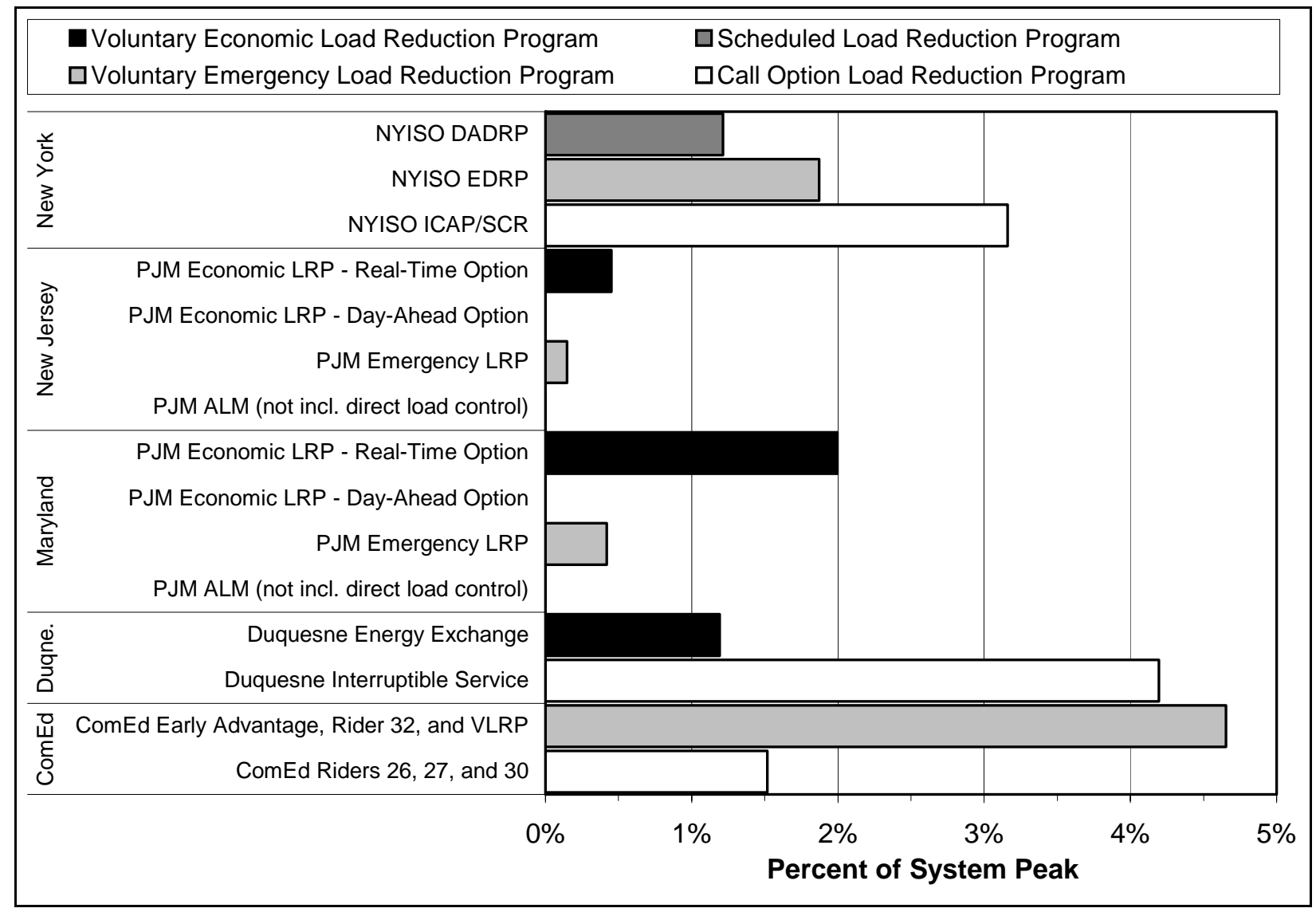

Figure 4. 2004 DR Program Enrollment (Participants’ Nominated/Contracted Load Reduction)

\section{Policy Implications and Recommendations Related to Developing Price Responsive Demand in Competitive Retail Markets}

Default RTP indexed to day-ahead market prices can be an effective strategy for simultaneously supporting retail market development and demand response. 
Default RTP rates indexed to the day-ahead market have a demonstrated track record of fostering the development of price responsive demand, while retaining the essential features that make hourly pricing an attractive default service. ${ }^{\mathrm{m}}$ In contrast, for those states and utilities with default RTP indexed to real time market prices (i.e. New Jersey, Maryland, and Duquesne), we know that switching rates from default service RTP are higher compared to those utilities with day-ahead hourly pricing and there are no empirical studies of customer price response to this tariff design.

\section{RTP is a means, but not necessarily and end to price response.}

The direct impact of default RTP on the development of price responsive demand depends on the amount of load remaining on rate. We found that some customers initially stay on RTP with no expectation of responding to hourly prices. However, over the long term, policymakers should expect that most customers will switch from default RTP.

Our interviews with competitive suppliers highlight two plausible (but untested) indirect beneficial impacts that default RTP may have on the development of price responsive demand. First, designating RTP, rather than a fixed price rate, as the default service may create additional demand for timedifferentiated pricing options in the competitive market, as some customers evidently use the default rate as a benchmark and seek out competitive contracts with a comparable pricing structure. ${ }^{\mathrm{n}}$ Second, customers' familiarity with, and acceptance of, hourly pricing may be enhanced as a result of education and training conducted as part of default RTP implementation, as well as from direct experience on default RTP. Through these experiences, customers that might otherwise be unfamiliar with, or disinclined towards, hourly pricing have an opportunity to become more knowledgeable about the potential benefits and the range of risk management options available. ${ }^{\circ}$ Indirect effects such as these are important to consider for both the design and evaluation of default service.

\section{The desired level of price response may not spring forth naturally.}

Our research reveals several encouraging signs regarding the development of price responsive demand in competitive retail markets. Hourly pricing options with various hedging options appear to be widely available in many regions. And early evidence suggests that, in at least several markets, a fairly sizable fraction (perhaps 50\% or more) of the large C\&I load has either remained on default RTP service or switched to a competitive supply service involving hourly pricing.

However, it is unclear whether hourly pricing arrangements offered by competitive suppliers have, or are likely to, induce a significant amount of price response. At present, suppliers offer few services to help customers identify, analyze, or implement load response strategies, which many suppliers attribute to the lack of customer demand for such services. Given consumers' entrenched habits and expectations, developed over decades of paying for their electricity at fixed prices, customer's load response to hourly pricing will be somewhat limited in the near to mid-term, without a concerted effort to help nurture and enhance their price response capabilities In many customer choice states, the

\footnotetext{
${ }^{\mathrm{m}}$ If day-ahead default RTP service is adopted, regulators should fully account for the associated load forecasting risks and balancing costs born by the default supplier, to ensure that the default service does not interfere with competitive suppliers' ability to offer day-ahead hourly pricing.

${ }^{\mathrm{n}}$ As an indication that competitive suppliers recognize this dynamic, several of the suppliers we interviewed explicitly market their hourly pricing service as a "guaranteed savings" product in regions with default RTP.

${ }^{\circ}$ An anecdote supporting this hypothesis: one supplier reported that some of its customers that had previously been on default RTP decided that hourly pricing “wasn’t so bad” and subsequently sought out a similar pricing arrangement in the competitive market.
} 
regulatory commission and utilities have conducted general customer education activities to provide basic information about restructuring and/or default service. Policymakers should consider using these forums as an opportunity to help customers better understand the potential cost savings and risk management benefits associated with load response to hourly spot market prices. Additional programmatic efforts, such as facility DR audits, customer training, and financial assistance with DR enabling technologies should also be considered, perhaps in conjunction with energy efficiency and load management initiatives.

\section{A wide array of data needs to be collected and analyzed to help policymakers and other stakeholders gauge the development of price responsive demand in competitive retail markets.}

A variety of policy and planning decisions (e.g., related to continuation of wholesale market price caps or certain types of DR programs) hinge on the degree of the price responsiveness of retail electricity consumers. Yet, little information is currently being collected in competitive retail markets regarding either the amount of load facing price signals that might motivate price response (e.g., hourly pricing) or the price responsiveness of those customers. Federal and state regulators and ISO/RTOs should consider undertaking efforts to regularly collect and analyze data on retail customers' supply arrangements and response to hourly pricing and other dynamic pricing options. Periodic assessments of the number of customers and amount of load exposed and responsive to hourly prices is an important indicator for monitoring and assessing the competitiveness of wholesale and retail electricity markets.

\section{Reliability-based ISO (or utility) DR programs are necessary for responding to reliability events and complement dynamic retail pricing initiatives.}

Reliability-based DR programs have a demonstrated track record of obtaining load reductions of 1-3\% of the system peak when events are called. These DR programs provide explicit payments to customers for load reductions and can serve as a backstop to mitigate various contingencies that threaten the reliability of the power system. Such DR programs can serve as an effective complement to dynamic pricing initiatives at the retail level, by providing a training ground for customers to assess their load curtailment potential and obtain actual operational experience implementing load reduction strategies on short notice and by providing additional business opportunities for various types of DR service providers.

\section{References}

(1) Barbose, G., C. Goldman, R. Bharvirkar, N. Hopper, M. Ting and B. Neenan, 2005, "Real Time Pricing as a Default or Optional Service for C\&I Customers: A Comparative Analysis of Eight Case Studies,” Report to the California Energy Commission, Lawrence Berkeley National Laboratory: LBNL-57661, August.

(2) Constellation NewEnergy, 2005, Presentation at the Merrill Lynch Texas Power Trip, March 30.

(3) Goldman, C., N. Hopper, R. Bharvirkar, B. Neenan, R. Boisvert, P. Cappers, D. Pratt, and K. Butkins, 2005, "Customer Strategies for Responding to Day-Ahead Market Hourly Electricity Pricing,” Report to the California Energy Commission, Lawrence Berkeley National Laboratory, LBNL-57128, August.

(4) Suez (Suez Energy Resources North America, 2004, “Texas 2004 Energy Usage and Sourcing Trend Survey Analysis,” October 26.

(5) Suez, 2005, “Northeast Trend Survey,” January 24. 